\title{
Variations of Dermatological Findings in New-Borns of a Community Hospital in Nepal
}

\author{
Shrestha $A^{1}$, Shrestha $S^{2}$
}

\begin{abstract}
Introduction: Skin manifestations are common in neonates. The prevalence of skin changes and their association with neonatal and maternal factors are not adequately documented in Nepal. It is important to differentiate common benign skin lesions from infrequent skin changes that cause morbidity, requiring medical management. The objectives of this study were to determine the pattern of skin lesions in new-borns and their association with maternal and neonatal variables. Material and Methods: This was a prospective, cross-sectional study conducted in obstetric unit of the hospital from December 2016 to May 2017. Outborn babies and babies shifted to NICU were excluded. Results: A total of 935 new-borns were examined. The commonest skin lesions were Mongolian spot (66.7\%), Erythema toxicum (46.6\%), Milia (44.4\%), Epstein pearls $(26.4 \%)$ and Salmon patch (11.9\%). Mothers aged 35 years or older $(63.6 \%)$ had statistically significant association with Erythema toxicum $(p=0.01)$. Erythema toxicum was more in primiparity, term pregnancy and caesarean section delivery. Milia was associated with male babies. Salmon patch was seen more in term pregnancy. Congenital melanocytic nevus, haemangioma and port-wine stain were noted in three, two and one new-borns respectively, which alter morbidity and hence are important to diagnose in time. Conclusion: We found that $93.8 \%$ of neonates had at one or more skin lesions. The majority of skin lesions were benign and transient. Erythema toxicum was seen commonly in mothers aged 35 and more. Salmon patch was seen more in term pregnancy.
\end{abstract}

Key words: Dermatoses, Maternal, Neonatal
${ }^{1}$ Dr. Asim Shrestha, MBBS, MD Paediatrics Department of Paediatrics, ${ }^{2} \mathrm{Dr}$. Smriti Shrestha, MBBS, MD Department of Dermatology. Dhulikhel hospital, Kathmandu University hospital, Nepal.

\section{Address for correspondence \\ Dr. Asim Shrestha \\ E-mail:kums_asim@yahoo.com}

\section{Introduction}

The skin of the neonate differs from adult in several ways. The

thickness of new-born skin is $40 \%$ to $60 \%$ of that of adult skin. It has weaker intercellular attachment and produces lesser amount of sweat ${ }^{1}$.

Majority of skin changes are benign, physiological, transient and self-limited. However, they can be distressing for parents leading them to seek medical attention. Moreover, a small number of skin lesions in new-born maybe medically significant, requiring intervention.

This work is licensed under a Creative Commons Attribution 3.0 License. 
Skin changes are seen in most of the new-borns. Moreover, various maternal and neonatal factors may be associated with specific skin lesions. However, there is paucity of data related to skin changes in new-borns in Nepal.

\section{Material and Methods}

This was a prospective, cross sectional study conducted in obstetric unit of the hospital, from December 2016 to May 2017. All babies born during this six months period were included. Babies born outside the hospital, stillbirths and babies requiring NICU admission were excluded.

Thorough examination of the new-borns was done. The neonates were undressed and examined in broad day light from head to toe for skin changes. The age, ethnicity and parity of mothers were noted. The gestational age, mode of delivery, sex, birth weight of the new-borns were also noted.

Universal sampling method was used. Ethical approval was taken from the Institutional Review Committee (IRC). A written consent was taken from all parents. All obtained data were entered in Microsoft excel and analysed by SPSS 23. Descriptive data was tabulated in frequency and percentage. Bivariate analysis was done with chi-square test for categorical data.

\section{Results}

Total of 935 healthy new-borns were included in the study. Maternal and neonatal features are shown in tables 1,2 and 3 .

Table 1: Maternal features

\begin{tabular}{lcc}
\hline & Number $(\mathbf{n = 9 3 5 )}$ & Percentage (\%) \\
\hline Ethnicity & & \\
\hline Tamang & 265 & 28.3 \\
\hline Newar & 226 & 24.2 \\
\hline Brahmin & 200 & 21.4 \\
\hline Chhetri & 173 & 18.5 \\
\hline Dalit & 71 & 7.6 \\
\hline Age & & \\
\hline$<18$ yrs & 10 & 1.1 \\
\hline $18-34$ yrs & 881 & 94.2 \\
\hline$>34$ yrs & 44 & 4.7 \\
\hline Parity & & \\
\hline Primi & 578 & 61.8 \\
\hline Multi & 357 & 38.2 \\
\hline
\end{tabular}

Table 2: Period of gestation and mode of delivery

\begin{tabular}{|c|c|c|}
\hline & Number $(n=935)$ & Percentage (\%) \\
\hline \multicolumn{3}{|c|}{ Period of gestation } \\
\hline$<37$ weeks & 51 & 5.5 \\
\hline 37- 42 weeks & 881 & 94.2 \\
\hline$>42$ weeks & 3 & 0.3 \\
\hline \multicolumn{3}{|c|}{ Mode of delivery } \\
\hline Vaginal & 655 & 70.1 \\
\hline Caesarean & 275 & 29.4 \\
\hline Instrumental & 5 & 0.5 \\
\hline
\end{tabular}

Table 3: Neonatal features

\begin{tabular}{|c|c|c|}
\hline & Number $(n=935)$ & Percentage (\%) \\
\hline \multicolumn{3}{|l|}{ Gender } \\
\hline Male & 492 & 52.6 \\
\hline Female & 443 & 47.4 \\
\hline \multicolumn{3}{|l|}{ Weight } \\
\hline$<2.5 \mathrm{~kg}$ & 121 & 12.9 \\
\hline$>2.5 \mathrm{~kg}$ & 814 & 87.1 \\
\hline
\end{tabular}

In this study, $93.8 \%$ cases had at least one skin lesion. Mongolian spot $(66.7 \%)$ was the commonest skin lesion noted, followed by Erythema toxicum (46.6\%), Milia (44.4\%), Epstein Pearl (46.6\%), salmon patch $(11.9 \%)$ respectively (Table 4$)$.

Table 4: Common skin findings

\begin{tabular}{lcc}
\hline Skin Lesions & Number (n) & Percentage (\%) \\
\hline Mongolian spot & 624 & 66.7 \\
\hline Erythema toxicum & 436 & 46.6 \\
\hline Milia & 415 & 44.4 \\
\hline Epstein pearl & 247 & 26.4 \\
\hline Salmon patch & 111 & 11.9 \\
\hline Milaria & 22 & 2.4 \\
\hline Pustulosis & 6 & 0.6 \\
\hline Congenital & 3 & 0.3 \\
melanocytic nevus & & \\
\hline Hemangioma & 2 & \\
\hline Port wine stain & 1 & \\
\hline
\end{tabular}

Common cutaneous lesions and their association with maternal and neonatal variables are shown in Table 5.

Erythema toxicum was associated with increasing maternal age, as $63.6 \%$ of the mothers aged 35 and above had erythema toxicum, which was statistically significant $(p$ value $=0.01)$ as shown in Table 6. Erythema toxicum was also more in primiparity, term and post term deliveries and caesarean section deliveries $(p>0.05)$. 
Table 5: Cutaneous lesions and related maternal and neonatal factors

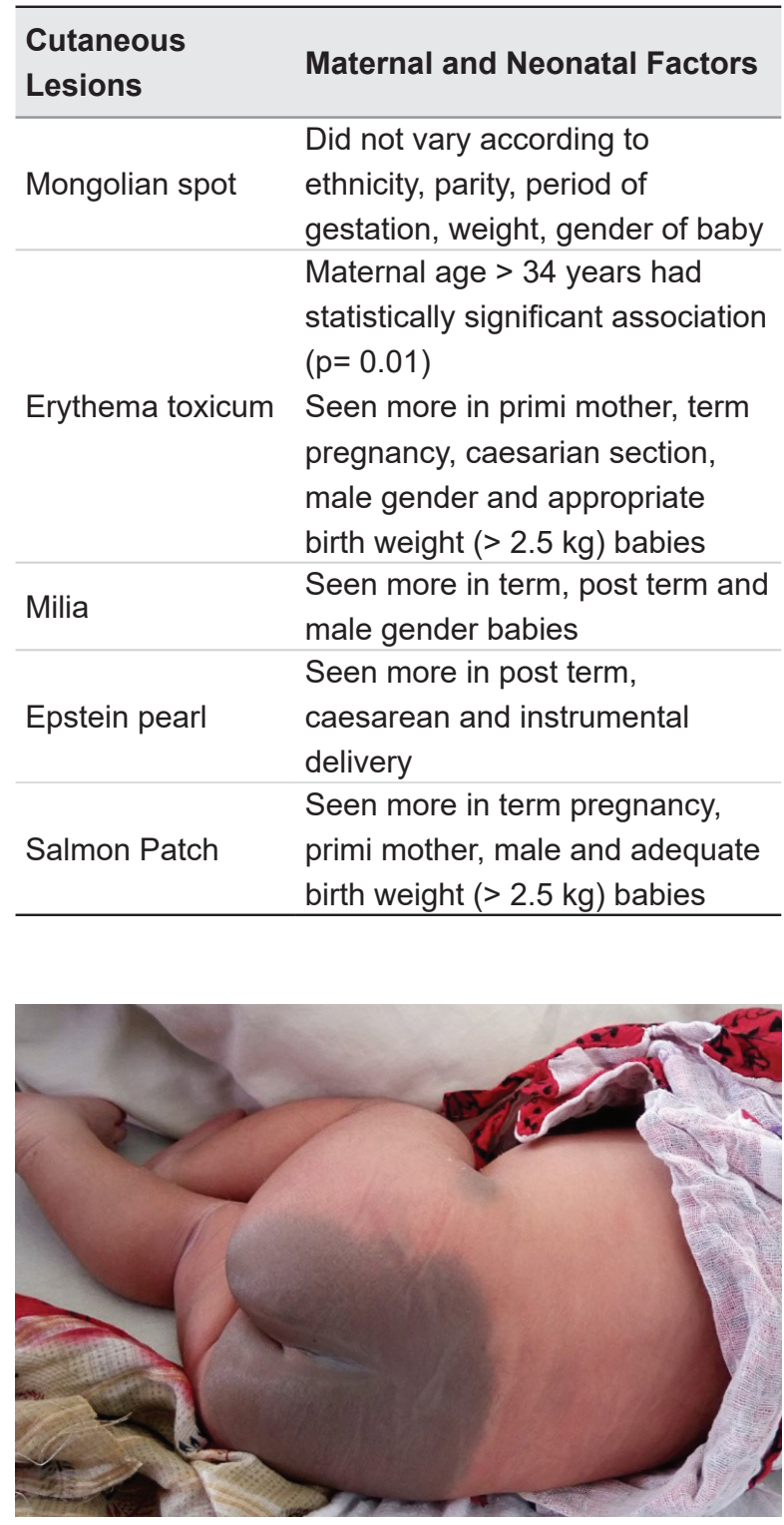

Fig 1: Showing Mongolian spot on the buttocks

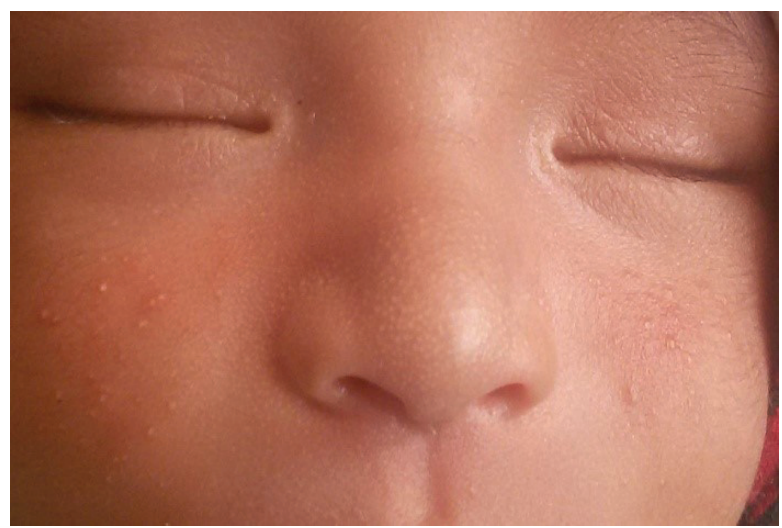

Fig 3: Milia is seen on the tip of the nose and cheeks
Table 6: Relation of Erythema toxicum with maternal age

\begin{tabular}{ccc}
\hline $\begin{array}{c}\text { Maternal Age in years } \\
\text { (Number) }\end{array}$ & $\mathbf{n ~ ( \% )}$ & p-value \\
\cline { 1 - 2 }$<18$ & $2(20)$ & \\
\cline { 1 - 2 } $18-34$ & $406(46.1)$ & 0.01 \\
\hline$>34$ & $28(63.6)$ & \\
\hline
\end{tabular}

${ }^{*} p$-value of $<0.05$ is statistically significant.

Similarly, milia was seen more in term and post term babies. Epstein pearls were seen more in post term babies and caesarean and instrumental delivery. Salmon patch was seen more in term pregnancy and primiparous mother, but it was statistically insignificant.

There were three babies with congenital melanocytic nevus, two with haemangioma and one with port wine stain. All underwent dermatological consultation.

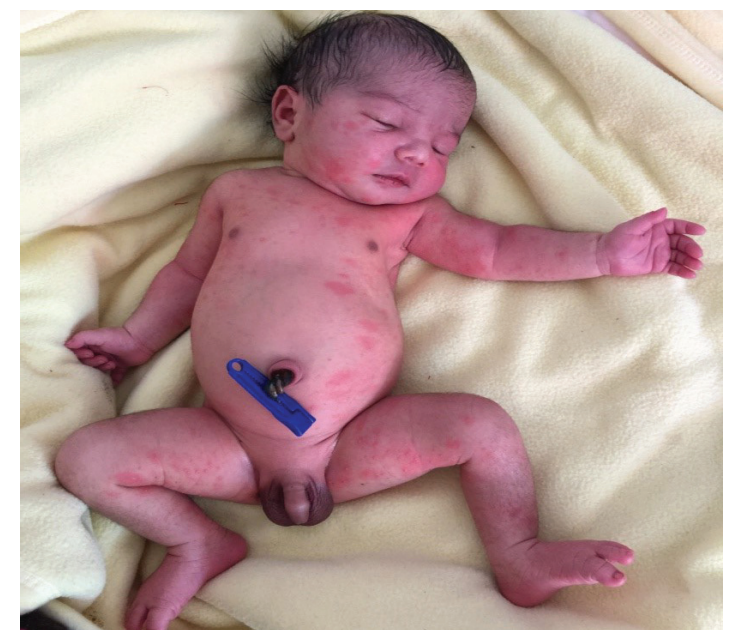

Fig 2: Erythema toxicum is seen on the face, trunk, abdomen and the extremities

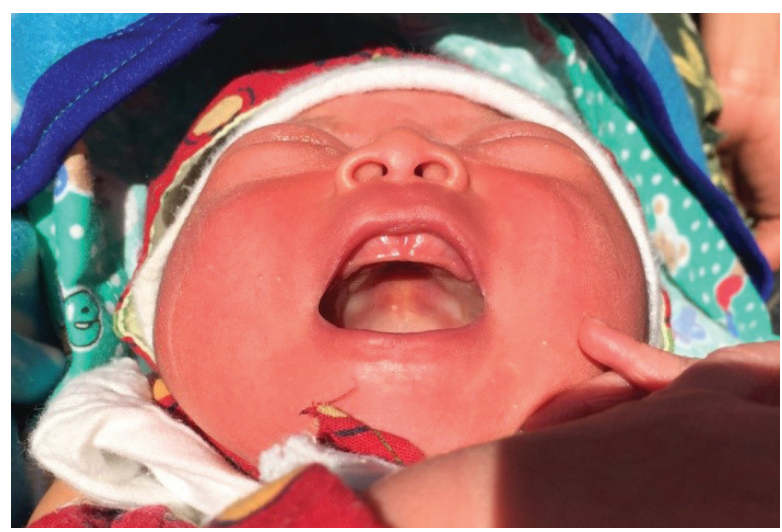

Fig 4: Epstein pearl is seen on the junction between the hard and soft palate 


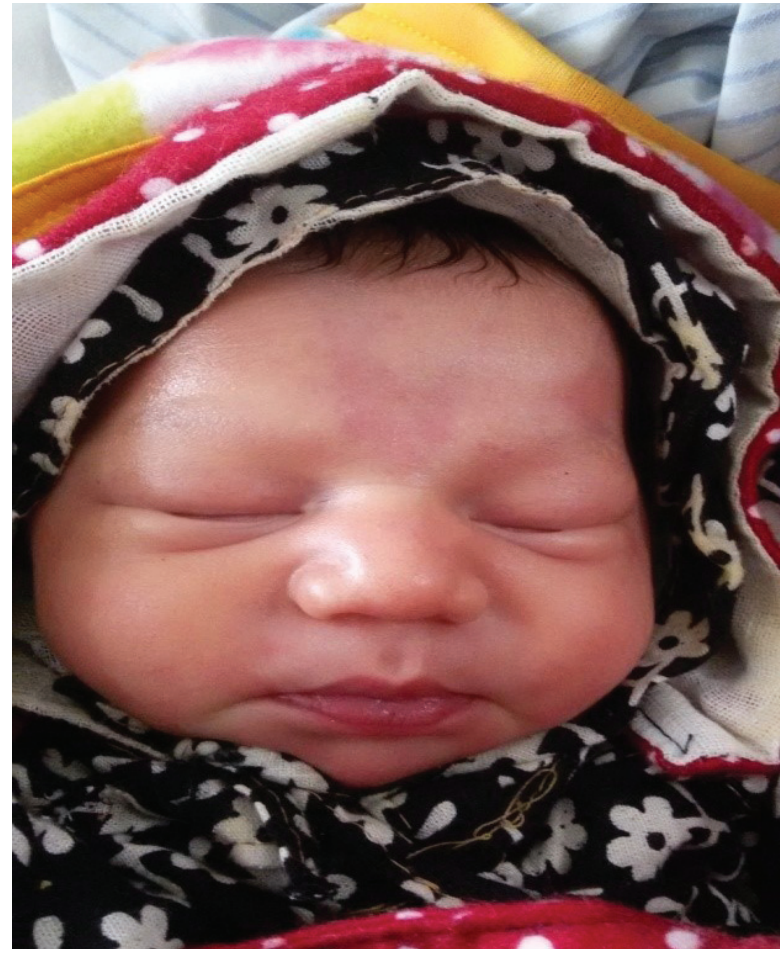

Fig 5: Salmon patch is seen on the forehead

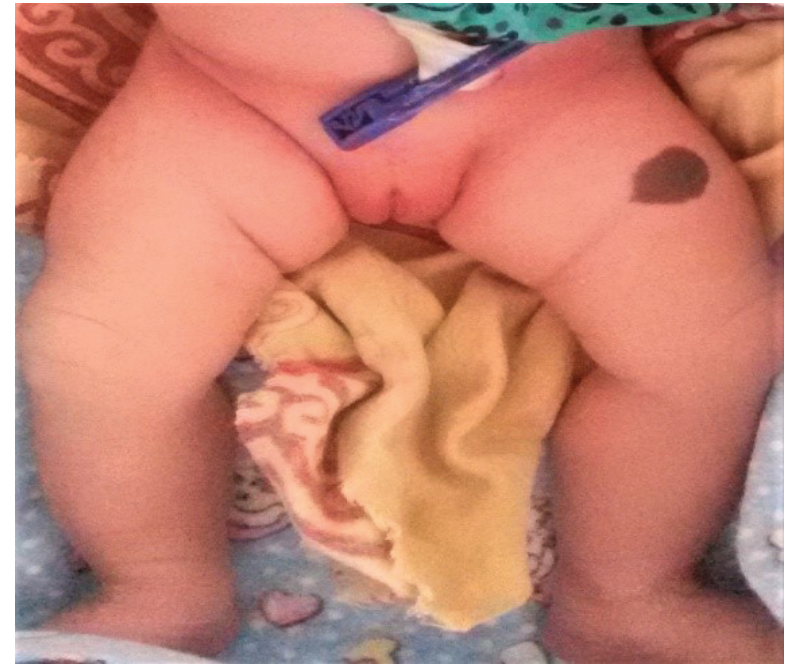

Fig 6: Congenital melanocytic nevus nevus is seen on the left thigh

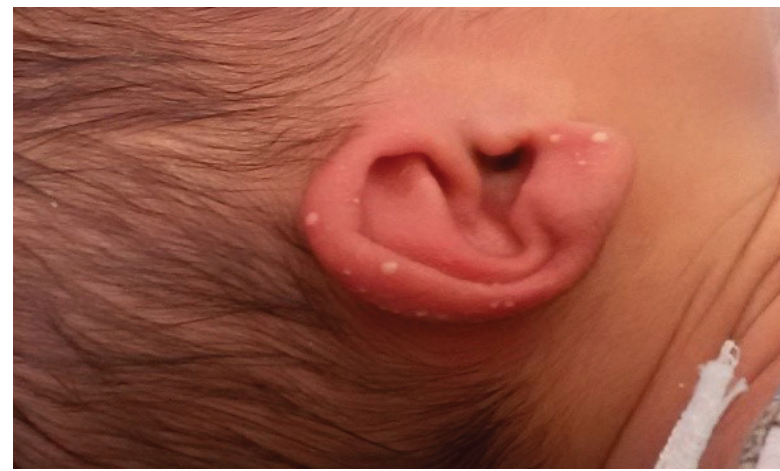

Fig 7: Pustulosis is seen on the helix and lobule of right ear

\section{Discussion}

Among many studies conducted regarding skin manifestations in new-borns, different findings are reported in various countries. We aimed to assess the prevalence of various skin changes and their correlation with maternal and neonatal factors, if any.

The prevalence of neonatal cutaneous findings has been reported to be between $57 \%$ to $99.3 \%$ in literature ${ }^{2,3,4,5}$. In this study, $93.8 \%$ of the new-borns had one or more skin changes, similar to previous reports. Interestingly, Nobby et al. observed pathological skin changes in $41 \%$ of the new-borns ${ }^{6}$. The authors have regarded erythema toxicum and nevus as pathological entities, which is subject to discussion, but is outside the scope of this article. A study from western Nepal showed $63 \%$ of the babies presented with more than one cutaneous manifestation, which is similar to our study with $65.4 \%$ neonates having more than one skin change ${ }^{7}$.

In our study, Mongolian spot was the commonest skin change noted among new-borns, seen in $66.7 \%$ of the cases. However, their frequency showed marked racial difference in literature, varying from $25.5 \%$ to $81.5 \%$ among different populations worldwide $3,8,9,10,11$. In accordance with our study, higher incidence has been recorded in Asian population ${ }^{12}$. This probably owes to higher melanin density among Asians, since Mongolian spot is also a dermal melanocytosis. Mongolian spot results from entrapment of melanocytes in the dermis during their migration from the neural crest into the epidermis ${ }^{13}$.

Mongolian spots were not associated with maternal and neonatal factors assessed in our study, such as age and parity of mothers and gestational age, gender and birth weight of the new-born, as well as mode of delivery. However, Asha et al. reported positive association of Mongolian spot with maternal illness ${ }^{14}$. They proposed that maternal illness interfere with migration of melanocytes to epidermis. We have not compared this correlation in our study.

In this study, occurrence of ETN (46.6\%)was consistent with previous reports ${ }^{4,15}$. We found significant association of ETN with increasing maternal age and $63.6 \%$ of the mothers were aged more than 34 years $(p=0.018)$. ETN was also more in primiparity, caesarean section delivery, male gender and appropriate birth weight $(>2.5 \mathrm{~kg}$ ) but not statistically significant. Ekiz et al. found ETN to be significantly associated with caesarean section delivery and multiparity ${ }^{16}$. 
The relationship between maturity and ETN has been reiterated in multiple studies ${ }^{4,17}$. ETN occurs in $30-50 \%$ of full-term infants, and $5 \%$ of preterm infants $^{18}$. It was postulated that an immunologically mature skin is required to produce the reaction pattern of ETN, producing more lesions in term and post-term neonates ${ }^{19}$. In our study, although ETN occurred more frequently in term(46.9\%) and post term (66.7\%) babies compared to preterm $(41.2 \%)$, the difference was not statistically significant. Rivers et al. and Ekiz et al. did not find significant relation with maturity ${ }^{3,16}$.

Milia was observed in $44.4 \%$ of our patients, similar to previous reports ${ }^{1,3}$. However, previous study in Nepal showed lower prevalence $(23.6 \%)$ of milia ${ }^{7}$. Gokdemir's et al. ${ }^{20}$ showed that milia was significantly associated with female gender, however in our study, it was more in male babies (M:F=1.13:1), although not statistically significant.

Epstein pearls were present in $26.4 \%$ of the babies. However, they were observed between $18.8 \%$ to $88.7 \%$ cases in various studies $2,3,7,9$. This wide variation in their prevalence could be because of racial and ethnic diversity. Also, oral mucosa was not examined in some studies.

Salmon patch was seen in $11.9 \%$ of our cases, while its incidence is variable ranging from $3.15 \%$ to $59 \%^{3,20,21}$. Multiple studies reported higher incidence of salmon patch in females ${ }^{11,21,22,23,24}$. But it was slightly higher in males in our study. Term new-borns had significantly more lesions of salmon patch compared to preterm (12.5\% VS $2 \%)$. Salmon patch was also more in new-borns with adequate birth weight $(>2.5 \mathrm{~kg})$ ( $p$ value $=0.22$ ). Our results coincide with previous reports stating that SP is more in term or post-term infants with heavier birth weight ${ }^{25,26}$.

Among vascular and pigmentary changes, there were three cases of congenital melanocytic nevi(CMN), two cases of haemangioma and one case of port wine stain. Approximately $1 \%$ of live births are affected with

\section{References}

1. KhoshnevisasI P, Sadeghzadeh M, Mazloomzadeh S, Zanjani AA. The Incidence of Birthmarks in Neonates Born in Zanjan, Iran. J Clin Neonatol 2015;4(1):8-12. DOI:10.4103/2249-4847.151158

2. Moosavi Z, Hosseini T. One-year survey of cutaneous lesions in 1000 consecutive Iranian newborns. Pediatr Dermatol 2006;23:61-3. DOI:10.1111/j.15251470.2006.00172.x
$\mathrm{CMN}$, which has 1-2 \% risk of malignant transformation into melanoma ${ }^{27}$. Giant CMN ( $>20 \mathrm{~cm}$ size) is rare, seen in <1:20000 live births and has risk of melanoma in $5-10 \%$ of cases $^{28}$. None of the CMN observed in our study were giant. However, since there is small but significant risk of melanoma in all cases of CMN, it is essential to counsel and follow up consistently.

Haemangiomas are generally innocuous but may be life threatening when it occurs near orifices such as airway ${ }^{29}$. Port wine stains can be isolated or associated with syndromes affecting multiple organs ${ }^{30}$.

Hence it is essential that medical persons be well acquainted with these skin changes, in order to differentiate benign and pathological findings. We want to highlight that this knowledge is invaluable among health officers and medical assistants in the context of a developing country, where all new-borns are not examined by specialists. It will aid in avoidance of inadvertent treatment, as well as delineate lifethreatening situations requiring further management.

\section{Conclusion}

Skin changes in new-borns is of frequent occurrence, most of which are benign. However, it is essential to differentiate physiological, harmless entities from less common but alarming findings, that alter morbidity or quality of life. Recognition and understanding of these conditions will help reduce the parental concern and anxiety. Among the maternal and neonatal variables, erythema toxicum was associated with increased maternal age.

Acknowledgement: We thank the interns, medical officers and residents of the Department of Paediatrics in our hospital for their help and cooperation during the study.

\section{Funding: None \\ Conflict of Interest: None \\ Permission from IRB: Yes}

3. Rivers JK, Frederiksen PC, Dibdin C. A prevalence survey of dermatoses in the Australian neonate. $J A m$ Acad Dermatol 1990;23:77-81.

4. Osburn K, Schosser RH, Everett MA. Congenital pigmented and vascular lesions in newborn infants. $J$ Am Acad Dermatol 1987; 16:788-92.

5. Reginatto FP, DeVilla D, Muller FM, Peruzzo J, Peres LP, Steglich RB. Prevalence and characterization of neonatal skin disorders in the first $72 \mathrm{~h}$ of life. J Pediatr (Rio J) 2017;93(3):238-45. http://dx.doi.sorg/10.1016/j. jped.2016.06.010 
6. Nobby B, Chakrabarty N. Cutaneous manifestations in the newborn. Ind J Dermatol Venereol Leprol (serial online). 1992;58:69-72. Available from: http://www. ijdvl.com/text.asp?1992/58/2/69/3753

7. Basnet S, Sathian B, Kumar A, Malla T. Clinicoepidemiological Study of Cutaneous Findings in Neonates in a Hospital Setting in Nepal. Indian J Neonatal Med Res 2016;4(1):1-6. DOI:10.7860/ IJNMR/2016/16572.2103

8. Oyedeji OA, Joel-Medewase VI, Ogunlesi TA, Oyedeji GA. Dermatoses in Nigerian Newborn. Res J Med Sci 2008;2(1):19-22. DOI: rjmsci.2008.19.22

9. Nanda A, Kaur S, Bhakoo ON, Dhall K. Survey of cutaneous lesions in Indian newborns. Pediatr Dermatol 1998;6:39-42.

10. Budair F, Aljabre $\mathrm{S}$, Alquorain N, Alnafea N, Aljabre A, Alburaey A. Survey of cutaneous findings in newborns in Saudi Arabia. J Dermatol Dermatologic Surg 2017;21(2)53-7. http://dx.doi.org/10.1016/j. jdds.2016.12.001

11. Hidano A, Purwoko R, Jitsukawa K. Statistical survey of skin changes in Japanese neonates. Pediatr Dermatol 1986;3(2):140-4.

12. Jacobs $A H$, Walton $R G$. The incidence of birthmarks in the neonate. Pediatrics 1976;58(2):218-22.

13. Leung AK, Robson WL. Superimposed Mongolian spots. Newborns Pediatr Dermatol 2008;25(2): 233-5. DOI:10.1111/j.1525-1470.2008.00641.x

14. Asha GS, Shilpa VK, Ramesh M, Revathi TN Clinical Study on Prevalence of Cutaneous Lesions in New Born Babies in India. Clin Exp Dermatol Res 2016;7(5):1-11. DOI: 10.4172/2155-9554.1000370

15. Liu C, Feng J, Qu R, Zhou H, Ma H, Niu X, et al. Epidemiologic study of the predisposing factors in erythema toxicum neonatorum. Dermatology 2005;210:269-72. DOI:10.1159/000084749

16. Ekiz O, Gul U, Mollamahmutoglu L, Gonul M. Skin Findings in Newborns and Their Relationship with Maternal Factors: Observational Research. Ann Dermatol 2013;25(1):1-4. http://dx.doi.org/10.5021/ ad.2013.25.1.1

17. Boccardi D, Menni S, Ferraroni M, Stival G, Bernardo L, Vechhia LC, et al. Birthmarks and transient skin lesions in newborns and their relationship to maternal factors: a preliminary report from northern Italy. Dermatology 2007;215:53-8. DOI:10.1159/000102034

18. Dragomir C, Florescu L, Buhus M. Erythema toxicum neonatorum. Rev Med Chir Soc Med Nat lasi 2006;110(4):797-800.
19. Carr JA, Hodgman JE, Freedman RI, Levan NE. Relationship between toxic erythema and infant maturity. Am J Dis Child 1966;112(2):129-34.

20. Gokdemir G, Erdogan HK, Köslü A, Baksu B. Cutaneous lesions in Turkish neonates born in a teaching hospital. Indian J Dermatol Venereol Leprol 2009;75(6):638. DOI: 10.4103/0378-6323.57742

21. Monteagudo B, Labandeira J, Acevedo A, Cabanillas M, León-Muiños $E$, Fernández-Prieto $R$ et al. Physiological Desquamation of the Newborn: Epidemiology and Predisposing Factors. Actas Dermosiliogr 2011;102:391-4. DOI: 10.1016/S15782190(11)70828-9

22. Shih $\mathrm{IH}$, Lin JY, Chen $\mathrm{CH}$, Hong HS. A birthmark survey in 500 newborns: clinical observation in two northern Taiwan medical center nurseries. Chang Gung Med J 2007;30(3):220-5.

23. Kahana M, Feldman M, Abudi Z, Yurman S. The incidence of birthmarks in Israeli neonates. Int $J$ Dermatol 1995;34(10):704-6.

24. Maher MH, Abady MH , Tabrizi A. Salmon Patch and Mongolian Spot Frequency in the Northwest of Iran: A Descriptive Study. Iranian J Neonatol 2016;7(3):24-8. DOI: 10.22038/IJN.2016.7651

25. Ferahbas A, Utas S, Akcakus M, Gunes T, Mistik S. Prevalence of cutaneous findings in hospitalized neonates: a prospective observational study. Pediatr Dermatol 2009;26(2):139-42. DOI:10.1111/j.15251470.2009.00903.x

26. Sachdeva M, Kaur S, Nagpal M, Dewan SP. Cutaneous lesions in new born. Indian J Dermatol Venereol Leprol 2002; 68(6):334-37.

27. Kinsler VA, O'Hare $P$, Bulstrode $N$, Calonje JE, Chong JE, Hargrave D et al. Melanoma in congenital melanocytic naevi. Br J Dermatol 2017;176:1131-143. DOI:10.1111/bjd.15301

28. Viana AC, Gontijo B, Bittencourt FV. Giant congenital melanocytic nevus. An Bras Dermatol 2013;88(6):86378. DOI: 10.1590/abd1806-4841.20132233

29. Sethuraman G, Yenamandra VK, Gupta V. Management of Infantile Hemangiomas: Current Trends. J Cutan Aesthet Surg 2014;7(2):75-85. DOI:10.4103/09742077.138324

30. Minkis K, Geronemus RG, Hale EK. Port Wine Stain Progression: A Potential Consequence of Delayed and Inadequate Treatment? Lasers Surg Med 2009;41(6):423-26. DOI:10.1002/lsm.20788. 